\title{
THE DESIGN OF VISUAL COMMUNICATION DESIGN MEDIA SHAPED PRODUCT CATALOG AS A MEDIUM OF PROMOTION AND INFORMATION ON PT TRANS NUSANTARA ACCESS (AUTHORIZED DEALER XL) TANGERANG
}

\author{
Ari Asmawati ${ }^{1}$ \\ Yuni Hafita ${ }^{2}$ \\ Muhammad Faisal ${ }^{3}$ \\ ${ }^{123}$ Perguruan Tinggi Raharja \\ 1,2,3 Jl.Jendral Sudirman No.40,modern,Tangerang,021-5529692 \\ Email : ariasmawati@raharja.infol, ${ }^{1}$ uni.hafita@raharja.info2, muhammadfaisal@raharja.info ${ }^{3}$
}

\begin{abstract}
ABSTRAK
Ilmu pengetahuan dan teknologi informasi berkembang cukup pesat dan menghasilkan inovasiinovasi baru yang senantiasa terus berubah ke era yang lebih baik. Informasi menjadi kata kunci dalam berbagai aspek kehidupan, siapa yang dapat menguasai informasi, baik pengusaha dalam proses penyajian, maupun pendapatan, ia akan bisa bertahan ditengah persaingan yang sedemikian ketat. Dengan alasan inilah perhatian terhadap proses informasi menjadi sangat ditekankan. Teknologi informasi khususnya teknologi berbasis multimedia diharapkan dapat memberikan peranan penting dalam proses penyaluran informasi, aplikasi multimedia mampu menghasilkan suatu informasi menjadi lebih efektif dan komunikatif.
\end{abstract}

Kata kunci: Promosi, Visual, Multimedia.

\section{ABSTRACT}

Science and information technology is evolving quite rapidly and produce new innovations are constantly changing to a better era. Information into keyword in various aspects of life, who can master the information, whether entrepreneurs in the process of rendering, as well as income, he will be able to survive in the middle of such a tight competition. With this reason attention to process information became very stressed. Information technology multimedia-based technologies in particular are expected to provide an important role in the process of channelling information, multimedia application capable of generating information to be more effective and communicative.

Keywords: promotion, Audio Visual, Video Profile.

\section{PENDAHULUAN}

Bentuk aplikasi multimedia yang digunakan adalah media komunikasi visual, yang merupakan sebuah sarana promosi ataupun sosialisasi yang efektif dalam penyampaian kemasyarakat luas. Oleh karena itu pengguna pengguna media komunikasi visual sangat dibutuhkan dalam pengenalan diri sebuah perusahaan atau lembaga. Pemberian informasi merupakan suatu usaha yang dibutuhkan perusahaan karena dengan adanya informasi perusahaan, maka perusahaan akan mendapatkan keuntungan yaitu dikenal secara luas.

Berdiri pada tanggal 6 Oktober 1989 dengan nama PT Graha metropolitan Lestari, XL mulai beroperasi sebagai perusahaan perdagangan barang dan jasa

Vol.2 No.1 - Februari 2016 
umum. Pada tahun 1996, XL memasuki sektor telekomunikasi setelah mendapatkan izin operasi GSM 900 dan secara resmi meluncurkan layanan GSM. Dengan demikian, XL menjadi perusahaan swasta pertama di Indonesia yang menyediakan layanan telepon selular. Perseroan mengubah nama menjadi PT Excelcomindo Pratama, sesuai dengan perjanjian kerja sama antara Grup Rajawali dan tiga investor asing (NYNEX, AIF, dan Mitsui).Setelah sembilan tahun menjadi perusahaan swasta, XL kemudian melakukan Penawaran Saham Perdana (IPO) pada September 2005 dan mendaftarkan sahamnya di Bursa Efek Jakarta, yang sekarang dikenal sebagai Bursa Efek Indonesia (BEI).

Dengan dilakukannya analisa terhadap permasalahan yang ada yaitu kurang lengkapnya informasi mengenai perusahaan ini dan belum terdapatnya katalog sebagai media promosi yang interaktif, maka penulis tertarik untuk merancang sebuah karya desain katalog produk, agar customer lebih percaya dan mengetahui lebih detail mengenai segala hal yang berkaitan dengan informasi tentang perusahaan. Serta dapat memudahkan bagian pemasaran dalam memperkenalkan seluruh kapasitas perusahaan dan diharapkan melalui proses perancangan ini dapat meningkatkan omset perusahaan.

\section{RUMUSAN MASALAH}

Saat ini perkembangan media promosi berkembang sangat pesat. Media yang banyak digunakan saat ini dapat berupa media komunikasi visual. Banyak Perusahaan-perusahaan yang sudah menggunakan media visual sebagai salah satu cara untuk mempromosikan suatu instansi perusahaan. Media visual merupakan media yang paling mudah dipahami dan dimengerti oleh calon Customer, karena di dalamnya terdapat unsur - unsur yang menarik, baik dari segi gambar yang mudah dimengerti dan di pahami.

Permasalahan yang melatar belakangi penelitian ini adalah kurangnya media katalog yang digunakan oleh PT. Akses Lintas Nusantara dalam mempromosikan secara keseluruhan apa yang ada dan disediakan oleh PT. Akses Lintas Nusantara, karena dalam melaksanakan suatu promosi masih menggunakan sebuah media promosi berupa media cetak, maka dari itu dibuatlah suatu teknik promosi baru untuk PT. Akses Lintas Nusantara dengan menggunakan Media Katalog.

\section{LANDASAN TEORI}

\section{Pengertian Perancangan}

Menurut Nasution, 2012:118. Perancangan adalah tahapan dimana dimulai mengenai bentuk input sistem, rancangan database, output sistem dan skema alur kerja program. Langkah awal dalam perancangan desain bermula dari hal-hal yang tidak teratur berupa gagasan atau ide-ide kemudian melalui proses penggarapan dan pengelolaan akan menghasilkan hal-hal yang teratur, sehingga hal-hal yang sudah teratur bisa memenuhi fungsi dan kegunaan secara baik.

Perancangan merupakan wujud visual yang dihasilkan dari bentuk-bentuk kreatif yang telah direncanakan. Langkah awal dalam perancangan desain bermula dari hal-hal yang tidak teratur berupa gagasan atau ide-ide kemudian melalui proses penggarapan dan pengelolaan akan menghasilkan hal-hal yang teratur, sehingga hal-hal yang sudah teratur bisa memenuhi fungsi dan kegunaan secara baik.

\section{Vol.2 No.1 - Februari 2016}


Menurut Iwan Binanto, (2010:260-261). Perancangan adalah tahap pembuatan spesifikasi mengenai arsitektur program, gaya, tampilan, dan kebutuhan material atau bahan untuk program. Tahap ini biasanya menggunakan storyboard untuk menggambarkan deskripsi tiap scene lain dan bagan alir (flowchart) untuk menggambarkan aliran dari satu scene ke scene lain.

Menurut Pujiriyanto 2012:27 Perancangan adalah wujud visual yang dihasilkan dari bentuk-bentuk kreatif yang telah direncanakan. Langkah awal dalam perancangan desain bermula dari hal-hal yang tidak teratur berupa gagasan atau ide-ide kemudian melalui proses penggarapan dan pengelolaan akan menghasilkan hal-hal yang teratur, sehingga hal-hal yang sudah teratur bisa memenuhi fungsi dan kegunaan secara baik.

\section{Konsep Dasar Media}

Menurut Maimunah dkk, Vol.5 No.3Mei 2012. Media adalah sarana untuk menyampaikan pesan atau informasi kepada publik dengan menggunakan berbagai unsur komunikasi grafis seperti teks, gambar atau foto.

\section{Konsep Dasar Desain}

\section{Pengertian Desain}

Supriyono, 2010:136. Desain merupakan art direction, yaitu penampilan visual secara menyeluruh dari iklan. Hasil kerja sama antara art direction dan copy writer (berupa konsep verbal dan visual) dipadukan secara sinergis kedalam desain melalui proses standar, yaitu membuat sketsa-sketsa kasar, menentukan alternative desain hingga final art work $(F A W)$.

\section{Konsep Dasar Komunikasi Visual}

Menurut Rakhmat Supriyono, 2010:9. Desain grafis belakangan lebih sering

Vol.2 No.1 - Februari 2016 disebut "Desain Komunikasi Visual" (DKV) karena memiliki peran mengomunikasikan pesan atau informasi kepada pembaca dengan berbagai kekuatan visual, seperti tipografi, ilustrasi warna, garis, layout dan sebagainya dengan bantuan teknologi.

\section{Definisi Katalog Produk}

Kotler dan Amstrong, 2012:236. Produk adalah segala sesuatu yang dapat ditawarkan untuk diperhatikan, dimiliki, digunakan, atau dikonsumsi yang dapat memuaskan keinginan dan kebutuhan. Produk mencakup objek fisik, jasa, orang, tempat, organisasi dan gagasan.

\section{Fungsi Katalog Produk}

Berikut beberapa fungsi katalog produk, diantaranya :

1. Untuk menawarkan atau menjual barang atau produk.

2. Sebagai alat yang efektif dan efisien.

3. Untuk menekan atau efisiensi biaya penjualan.

4. Sebagai alat memotivasi agen penjualan yang ampuh.

\section{Konsep Dasar Promosi}

menurut Lukiati Komala, 2010:54-59. Promosi adalah suatu bentuk komunikasi pemasaran. Yang dimaksud dengan komunikasi pemasaran adalah aktivitas pemasaran yang berusaha menyebarkan informasi, mempengaruhi atau membujuk dan mengingatkan pasar sasaran atas perusahaan dan produknya agar bersedia menerima dan loyal pada produk yang ditawarkan perusahaan yang bersangkutan.

Menurut Mukti Budiarto dalam jurnal CCIT Vol.1, 2011:57. Promosi adalah suatu bentuk kegiatan yang diselenggarakan oleh pihak pemasar yang bertujuan untuk menarik perhatian masyarakat, sehingga tertarik untuk melakukan transaksi seperti yang 
diinginkan oleh pihak pemasar, agar pelaksanaan program promosi dapat berjalan dengan baik, dan segala sesuatunya harus dipersiapkan dengan matang.

Dari kutipan di atas peneliti menyimpulkan bahwa promosi merupakan rangkaian kegiatan pemasaran yang bertujuan untuk memperkenalkan produk yang dihasilkan oleh produsen melalui jalinan komunikasi dengan maksud mempengaruhi dan mendorong konsumen untuk memberi produk yang ditawarkan. Kegiatan promosi dapat dilakukan langsung bertatap muka dengan calon konsumen (personal selling) atau dengan menggunakan media yang ada seperti media massa maupun elektronik.

\section{Konsep Dasar Informasi}

Yakup, 2012:8. Informasi (information) dapat didefinisikan sebagai berikut : "Informasi adalah data yang diolah menjadi bentuk yang lebih berguna dan lebih berarti bagi yang menerimannya, informasi disebut juga data yang diproses atau data yang memiliki arti”.

\section{Program Aplikasi Penunjang Desain Adobe Photoshop CS6}

Menurut Budi Permana dan Kurweni Ukar, 2010:2. Adobe Photoshop merupakan program tercanggih dan terpopuler saat ini ditujukan untuk menyunting dan memanipulasi gambar (image-editing). Program aplikasi ini banyak membantu para professional dalam dunia fotografi, pracetak, dan multimedia.

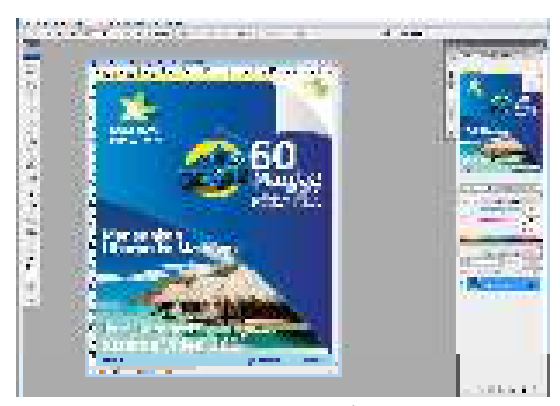

Gambar

Tampilan Area Kerja Adobe Photoshop CS6

\section{CorelDRAW}

Menurut Athenk Arts, 2012:01 CorelDraw adalah sebagai dasar pemahaman seni menggambar di komputer, yang lebih menekankan pada teknik penggunaan fasilitas dasar pada software berbasis CAD (Computer Aided Design)

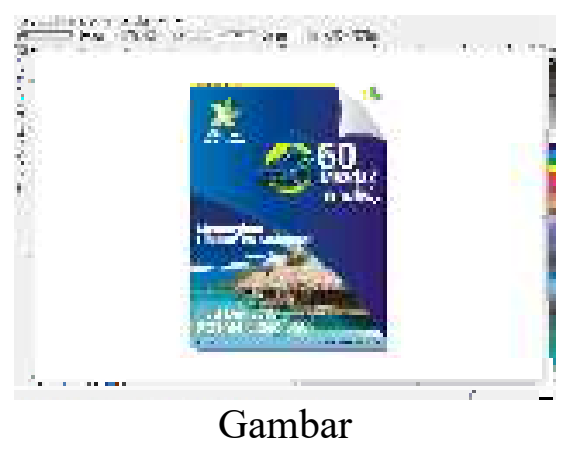

Tampilan Area Kerja Corel Draw

\section{Konsep Desain \\ Perencanaan Media}

Dalam hal ini, konsep media yang diajukan adalah perancangan media informasi dan promosi dalam bentuk sebuah desain katalog produk yang berukuran 21 x $29.7 \mathrm{~cm}$. Buku ini berisi cover depan, daftar isi, produk yang ada di katalog, promo terbaru, layanan kami dan our store, our stock daftar our activity, dan cover belakang. Semua isi yang terkait dalam perancangan desain katalog produk tersebut dikemas dengan

Vol.2 No.1 - Februari 2016 
menggunakan pengembangan kreatif desain grafis.

\section{Strategi Media}

Dalam menunjang nilai efektifitas sarana media yang dirancang strategi media promosi adalah dengan menggunakan bentuk media desain katalog produk, secara visual orientasi gambar-gambar tampilan dengan menggunakan teknik drawing yang diproduksi melalui aplikasi penunjang gambar vektor, hal tersebut secara visual untuk memenuhi 3 aspek sasaran yaitu:

1. Geografi : Dalam dan luar Kota Jakarta

2. Demografi :
a. Jenis Kelamin
: Pria \& Wanita
b. Kelas Ekonomi :Umum
(mencakup seluruh kelas ekonomi)
c. Sasaran
Konsumen individu atau perusahaan

3. Psikografi : Bagi konsumen khususnya yang memerlukan produk kartu XL dan AXIS.

\section{Perencanaan Pesan (Konsep Kreatif)}

Rancangan media yang direncanakan menampilkan sesuatu yang baru dan unik yaitu bergaya desain pop art yang lebih menonjolkan pada eksplorasi warna yang ramai, Serta diperjelas dengan teks-teks dan layout yang simple penjelasan secara sepintas, tampilan-tampilan pesan secara kreatif akan diolah, ditata sesuai dengan kebutuhan pesan yang direncanakan oleh pihak perusahaan.

\section{Perencanaan Visual}

Penyajian desain desain katalog dengan tetap mempertahankan warna-warna yang melambangkan identitas logo perusahaan seperti warna kuning dan hijau adalah warna yang berasal dari warna identik PT. Akses Lintas Nusantara (authorized dealer $\mathrm{xl}$ ), yang diolah dengan menggunakan kombinasi warna lain yang senada dengan warna aslinya. Untuk gambar, penulis menggunakan gambar dari browsing di internet seperti logo mitra kerja PT. Akses Lintas Nusantara (authorized dealer xl) dan foto-foto yang diambil oleh penulis sendiri dan diolah dengan menggunakan gabungan beberapa software pendukung yaitu Adobe Photoshop.

\section{Proses Desain (Designing) \\ Layout Kasar (Rough Layout)}

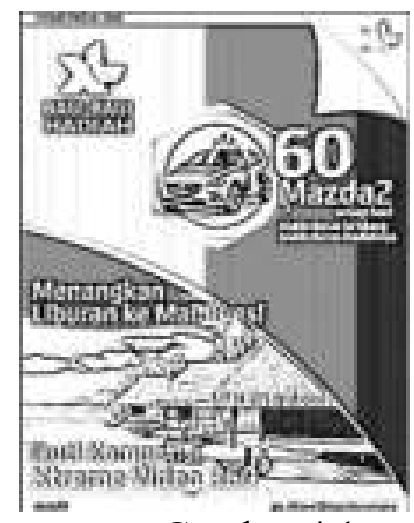

Gambar 4.1

Layout Kasar Cover Depan

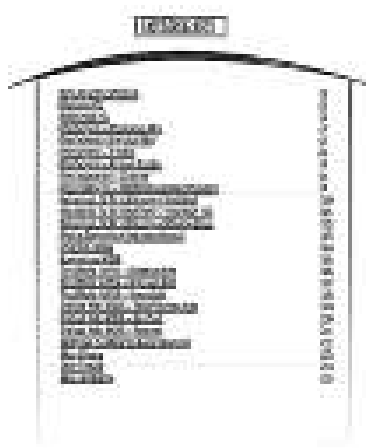

Gambar 4.2

Layout Kasar Daftra Isi.

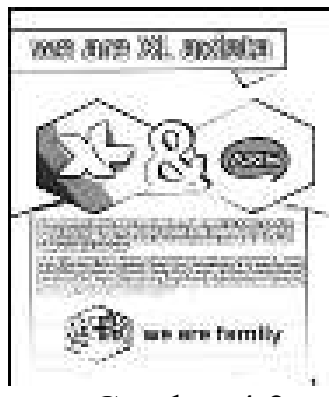

Gambar 4.3

Layout Kasar Halaman 1

Vol.2 No.1 - Februari 2016 


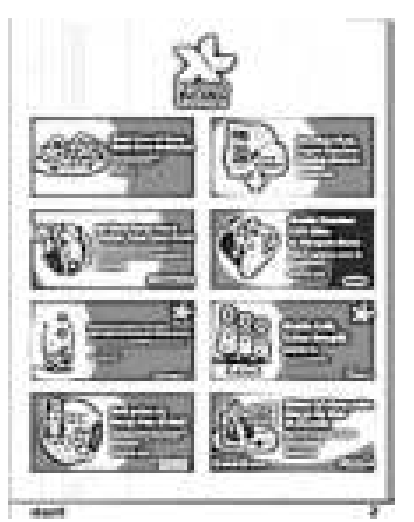

Gambar 4.4

Layout Kasar Halaman 2

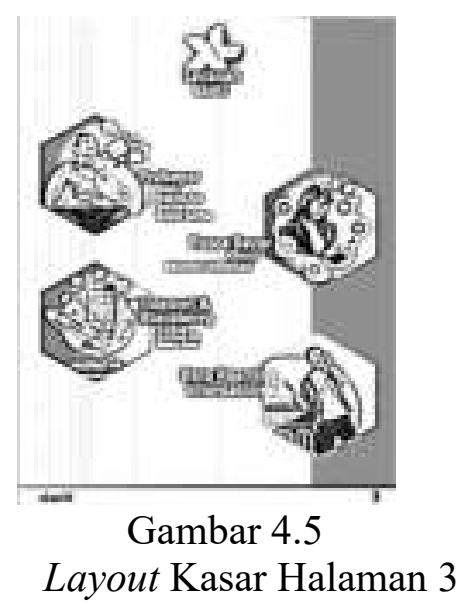

\section{Final Artwork}

Final Artwork adalah merupakan gambar kerja final yang telah melewati beberapa proses sebelumnya yaitu layout kasar dan layout komprehensif. Pada proses ini naskah serta tata letak gambar merupakan proses akhir yang siap diproduksi proses cetak atau jenis produksi media secara elektronik setelah disempurnakan dengan beberapa kali revisi selama proses desain.

\section{Final Artwork Cover Depan}

Cover Headline pada promosi ini menggunakan kata : "Menangkan Liburan Ke Maldives" dengan isi tulisan judulnya berwarna putih sedangkan Bagibagi Hadiah. Font yang digunakan pada halaman ini adalah Revisal Bold, Regular, Ultra thin dan hairline.

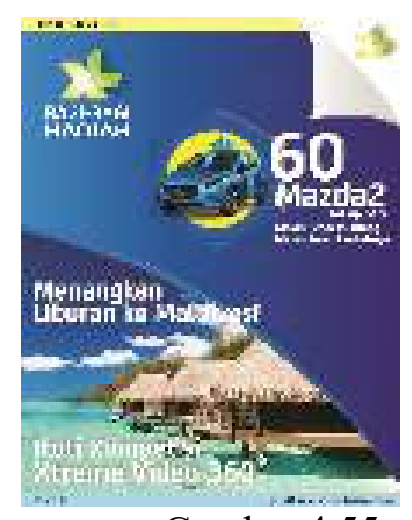

Gambar 4.55

Final Artwork Cover Depan.

\section{Final Artwork Daftar Isi}

Halaman daftar isi berisi foto produk dengan tata letak atau layout yang menarik dan font yang digunakan dalam halaman ini adalah Revisal dan Minion Pro.

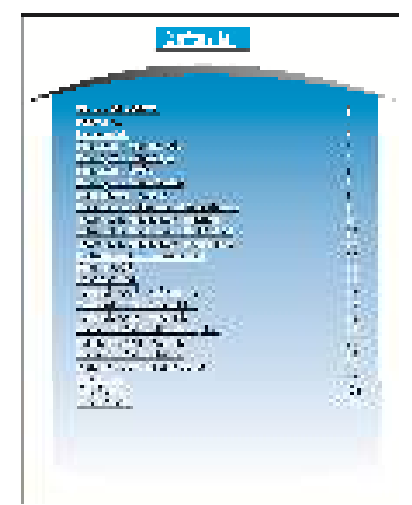

Gambar 4.56

Final Artwork Daftar Isi.

\section{Final Artwork Halaman 1}

Halaman 1 berisi logo XL dan berisi logo AXIS satu brand dari perusahaan yaitu PT. Akses Lintas Nusantara serta menjelaskan keunggulan yang dimiliki brand perusahaan ini. Font yang digunakan dalam halaman ini adalah Revisal. 


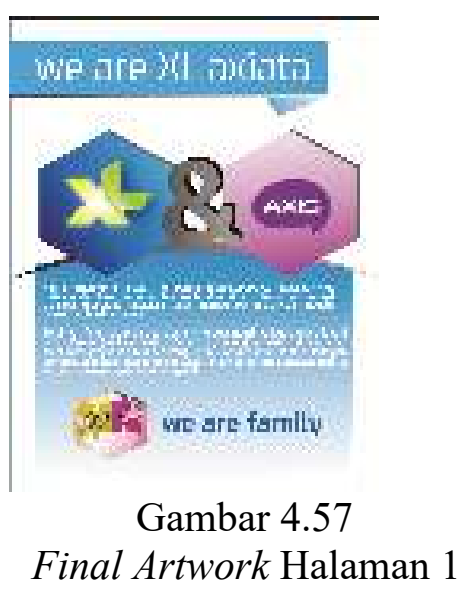

\section{Final Artwork Halaman 2}

Halaman 2 berisi foto Promosi terbaru dari perusahaan menjelaskan berbagai macam promo terbaru dari XL. Font yang digunakan dalam halaman ini adalah Revisal.

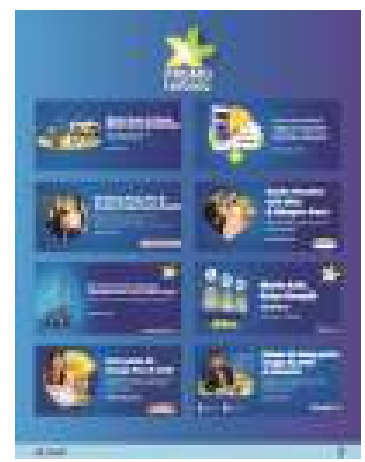

Gambar 4.58

Final Artwork Halaman 2

\section{Final Artwork Halaman 3}

Halaman 3 berisi layanan kami dari XL, serta menjelaskan menggunakan prabayar, menggunakan internet,data rooming internasional keunggulan yang dimiliki XL. Font yang digunakan dalam halaman ini adalah Revisal.

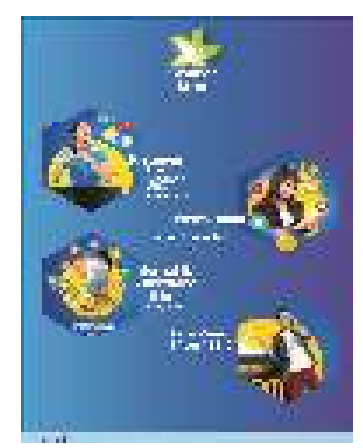

Vol.2 No.1 - Februari 2016
Gambar 4.59

Final Artwork Halaman 3

\section{Literature Review}

1. Pembuatan Katalog Buku Perpustakaan Berbasis Web, Sumatera Selatan adalah salah satu judul jurnal yang di buat oleh Muhamad Kadafi selaku mahasiswa Universitas Indo Global Mandiri, penelitian ini menjelaskan tentang pembuatan katalog buku perpustakaan yang berbasis web.

2. Aplikasi Katalog Islam Berbasis Web Pada Sekolah Tinggi Agama Islam Bakti Negara (Staibn) Tegal, Semarang adalah salah satu judul tugas akhir yang dibuat oleh Widiyono selaku mahasiswa Universitas Dian Nuswantoro Semarang, penelitian ini menjelaskan pembuatan aplikasi katalog islam yang berbasis web yang berada di Sekolah Tinggi Agama Islam Bakti Negara (Staibn) Tegal.

3. Analisis Penerapan E-Catalogue Di Pemerintahan, Jakarta adalah salah satu jurnal yang dibuat oleh Jackson Surianto selaku mahasiswa Universitas Bina Nusantara Jakarta, penelitian ini menjelaskan pembuatan analisis penerapan ECatalogue yang di pemerintahan jakarta.

\section{Daftar Pustaka}

[1] Arts, Athenk, 2012. Efek-efek Terbaik CorelDraw dan Photoshop, Penerbit Citra Media Pustaka, Jakarta

[2] Binanto, Iwan, 2010. Multimedia Digital Dasar Teori dan Pengembangannya, Penerbit Andi, Yogyakarta 
[3] Budiarto, Mukti, dkk.2011. Desain Media Komuniasi Visual Sebagai Penunjang Kegiatan Promosi Kampus, Journal CCIT Vol.1 No. 2. Tangerang : Perguruan Tinggi Raharja.

[4] Hendratman, Hendi, ST., 2014. Tips n Trix Computer Graphics Design, INFORMATIKA, Bandung,

[5] Ibnu Teguh, Wibowo, 2013. Belajar Desain Grafis, Penerbit Buku Pintar, Yogyakarta,

[6] Komala,Lukiati, 2010. Komunikasi Massa, Jakarta, Universitas Terbuka.

[7] Maimunah dkk, 2012. Jurnal CCIT, Perguruan Tinggi Raharja, Tangerang,

[8] Nasution, Ruslan Efendi. 2012. Implementasi SMS Gateway In The Development Web Based Informasi System Schedule Seminar Thesis. Lampung : Unila.

[9] O'Brien, 2012. Yakub Pengantar Sistem Informasi, Penerbit Graha Ilmu, Yogyakarta,

[10] Supriyono, Rakhmat. 2010. Desain Komunikasi Visual Teori dan Aplikasi. Yogyakarta: Andi

[11] Sutabri, Tata. 2012. Analisis Sistem Informasi. Yogyakarta : Andi Publisher. 